\title{
Immunohistochemical Expression of Chromogranins A and $B$, Prohormone Convertases 2 and 3, and Amidating Enzyme in Carcinoid Tumors and Pancreatic Endocrine Tumors
}

\author{
Noriko Kimura, M.D., Ph.D., Monika Pilichowska, M.D., Ph.D., Hiroshi Okamoto, M.D., Ph.D., \\ Itaru Kimura, M.D., Ph.D., Dominique Aunis, M.D. \\ Departments of Pathology (NK, MP) and Biochemistry (HO), Tohoku University School of Medicine, and \\ Department of Pathology (NK), Tohoku Rosai Hospital, Sendai; Department of Neurology (IK), National \\ Yamagata Hospital, Yamagata, Japan; and Biologie de Communication Cellulaire, Strasbourg Cedex, \\ France (DA)
}

\begin{abstract}
Although chromogranin A (CgA) is widely distributed in neuroendocrine tumors, the distribution of chromogranin B (CgB) has not been elucidated. Hormones produced by tumors are sometimes prohormones and not necessarily bioactive hormones. Prohormones have to be processed into bioactive peptides by prohormone convertases (PCs), and some of them have to be amidated by peptidylglycine $\alpha$-amidating monooxygenase (PGM). Whether PCs and PGM are present or not in tumors may explain why some tumors are functioning and some are nonfunctioning. We investigated 45 carcinoids and 16 pancreatic endocrine tumors. Of the carcinoids, CgA was expressed in most of the tumors, except for the rectal and ovarian carcinoids, which expressed CgB strongly. The expressions of PC2, PC3, and PGM were $31 \%, 100 \%$, and $87 \%$, respectively. In the pancreatic tumors, CgA was expressed in all tumors, whereas $\mathrm{CgB}$ was not expressed in any tumor. The expressions of PC2, PC3, and PGM were $63 \%, 88 \%$, and $63 \%$, respectively. PC3 was expressed in all of the functioning tumors but not in two of the four nonfunctioning tumors. PC2 and PGM were not expressed in three of the four nonfunctioning tumors. In conclusion, expression of CgA and CgB was different depending on the tumor location. High frequency of PCs and PGM may explain why even nonfunctioning tumors produce some inconspicuous peptides.
\end{abstract}

Copyright (C) 2000 by The United States and Canadian Academy of Pathology, Inc.

VOL. 13, NO. 2, P. 140, 2000 Printed in the U.S.A.

Date of acceptance: September 10, 1999.

Address reprint requests to: Noriko Kimura M.D., Ph.D., Department of Pathology, Tohoku Rosai Hospital, 21-3-4, Dainohara Aoba-ku, Sendai 981-0911, Japan; e-mail: nkimura@patholo2.med.tohoku.ac.jp; fax: 022$275-7541$.
KEY WORDS: Carcinoid, Chromogranin A, Chromogranin B, Immunohistochemistry, Peptidylglycine $\alpha$-amidating monooxygenase, Prohormone convertase.

Mod Pathol 2000;13(2):140-146

Carcinoids and pancreatic endocrine tumors are derived from the neuroendocrine system. Clinically, there are two types of neuroendocrine tumors: functioning and nonfunctioning. The term functioning is applied only to tumors that induce a clinical syndrome of endocrine hyperfunction as a result of inappropriately elevated serum hormone concentrations (1). Nonfunctioning tumors induce no clinical symptoms. Possible reasons that some tumors are nonfunctioning include the following: (1) The tumors produce hormones that have clinically inconspicuous functions (e.g., somatostatin, pancreatic polypeptide), (2) the tumors produce a small amount of hormones and are unable to induce clinical symptoms, (3) the tumors produce prohormones but not bioactive hormones, and (4) the tumor cells are unable to release hormones into the blood vessels. In both types of tumors, numerous secretory granules are present in the cytoplasm. Hormones are packed in the secretory granules with many other proteins. Chromogranin A (CgA) is a major component of the secretory granules and has been used as a tumor marker for neuroendocrine tumors (2-4). However, some carcinoids, especially from the rectum, have been known to be negative for CgA $(5,6)$. Chromogranin $\mathrm{B}(\mathrm{CgB})$ is also abundant in neuroendocrine cells and tumors, especially in the adrenal medulla and pituitary gland (7-9). Its distribution in carcinoids and pancreatic endocrine tumors is not known.

Neuroendocrine tumors usually produce hormones in the form of prohormones, which must be 
processed into bioactive peptides by prohormone convertase (PC) (10). PC2 and PC3 (also known as PC1) are members of a family of cellular endoproteolytic processing enzymes $(11,12)$. Many regulatory peptides require the $\alpha$-amidation of a carboxyl terminus for biologic activity or for binding to their receptors (13) by peptidylglycine $\alpha$-amidating monooxygenase (PGM) and peptidylamidoglycolate lyase, which are encoded in a single mRNA molecule $(14,15)$. PC2, PC3, and PGM are also contained in the secretory granules of the neuroendocrine system and of the tumors derived from it (16). PC2 and PC3 have been reported to be useful markers for neuroendocrine cells (17). In the present study, we performed immunohistochemical stainings of $\mathrm{CgA}, \mathrm{CgB}, \mathrm{PC} 2, \mathrm{PC} 3$, and PGM in carcinoids of various organs and pancreatic endocrine tumors to compare their expressions and functional states, and we examined the usefulness of these markers for making a pathologic diagnosis.

\section{MATERIALS AND METHODS}

Forty-five carcinoids ( 7 gastric, 2 ileum, 3 ovarian, 2 testicular, 2 thymic, and 29 rectal) and 16 pancreatic endocrine tumors were removed and fixed in $10 \%$ buffered formaldehyde and embedded in paraffin. Of the carcinoids, only the two thymic carcinoids were clinically functioning; they produced adrenocorticotropic hormone (ACTH) and induced Cushing's syndrome. The patients with other carcinoids had no endocrinologic symptoms, and the tumors were clinically considered to be nonfunctioning. The pathologic diagnosis of those tumors was made after surgery, and the hormone levels in the preoperative serum were not examined. Tumors that were examined only by immunohistochemical staining were not classified as functioning tumors even if many cells were positive for peptide hormones (e.g., most tumor cells of the testicular carcinoids showed serotonin immunoreactivity; they were classified as nonfunctioning tumors). The pancreatic tumors included 12 clinically functioning tumors-1 ACTH-producing tumor with Cushing's syndrome, 3 gastrin-producing tumors, and 8 insulin-producing tumors-and 4 nonfunctioning tumors. The tissue sections were immunohistochemically investigated with specific antibodies for human $\mathrm{CgA}, \mathrm{CgB}, \mathrm{PC} 2, \mathrm{PC}$, and rat PGM using the streptavidin-biotin peroxidase complex method. For the pancreatic endocrine tumors, insulin, glucagon, somatostatin, pancreatic polypeptide, gastrin, and ACTH were also immunohistochemically investigated to compare the clinical diagnosis and immunohistochemical study. The immunohistochemical procedures were the same as those described previously (3). The sources of the antibodies are summarized in Table 1. The antibody for PC3 was supplied by Dr. D.F. Steiner (18).

For positive controls, several sections were stained simultaneously: pheochromocytoma for $\mathrm{CgA}$ and $\mathrm{CgB}$ and the normal pancreas and pituitary gland for PC2, PC3, and PGM. For PGM antibody, immunospecificity was confirmed by Western blotting. The specificity of the antibody for $\mathrm{CgB}$ (CgB 548-564) raised by one of the authors (DA) was confirmed by adsorption test; $5 \mathrm{mg}$ of peptide was added to $1 \mathrm{~mL}$ of diluted antibody at 1:1000, then kept it at $37^{\circ} \mathrm{C}$ for $1 \mathrm{~h}$ and then at $4^{\circ} \mathrm{C}$ for $18 \mathrm{~h}$ at room temperature. After centrifuge, the supernatant was used for immunohistochemistry. Nonimmune rabbit serum was used instead of the specific primary antibodies as a negative control. Immunoreactivity was evaluated as follows: -, no immunoreactive cells; + , less than $20 \%$ of tumor cells immunoreactive; ++ , more than $20 \%$ of the tumor cells immunoreactive; +++ , more than $50 \%$ of the tumor cells immunoreactive.

\section{RESULTS}

CgA, CgB, PCs, and PGM were detected in the tissues of the positive controls. In the normal pancreas, CgA, PC2, PC3, and PGM were expressed in almost all cells of the pancreatic islets. $\mathrm{CgB}$ was focally observed in some of the islets with both antibodies. However, the majority of the islets had few cells that were immunoreactive for CgB. In addition, peripheral nerves were stained by the author's (DA) antibody but not by the Santa Cruz antibody. In the normal human adrenal medulla, the majority of cells showed strong immunoreactivity for CgB with both antibodies. The immuno-

TABLE 1. The Sources and Working Dilutions of the Primary Antibodies

\begin{tabular}{lll}
\hline Antibodies & \multicolumn{1}{c}{ Sources } & $\begin{array}{c}\text { Working } \\
\text { Dilution }\end{array}$ \\
\hline CgA & DAKO (Glostrup, Denmark) & $1: 1000$ \\
CgB & 1) Dr. D. Aunis raised against & $1: 3000$ \\
& human CgB 548-564 & \\
& 2) Santa Cruz Biotech (Santa Cruz, & $1: 2000$ \\
PC3 & CA) against human CgB 658-676 & \\
PC2 & Dr. Donald F. Steiner (18) & $1: 1000$ \\
& Chemicon (Temecula, CA), amino & $1: 200$ \\
PGM & acids 112-159 of human PC2 & \\
& 1) Dr. H. Okamoto, peptidylglycine- & $1: 2000$ \\
& $\alpha$-hydroxylase (37 kD) & \\
Insulin & 2) Dr. H. Okamoto, $\alpha$-hydroxyglycine & $1: 2000$ \\
Glucagon & amidating dealkylase (53 kD) & \\
Somatostatin & DAKO & $1: 3000$ \\
Pancreatic & DAKO & $1: 3000$ \\
polypeptide & DAKO & $1: 3000$ \\
Gastrin & DAKO & $1: 4000$ \\
ACTH & Incstar (Stillwater, MN) & $1: 3000$ \\
\hline
\end{tabular}

Cg, chromogranin; PC, prohormone convertase; PGM, peptidylglycine $\alpha$-amidating monooxygenase; ACTH, adrenocorticotropic hormone. 
histochemical results are summarized in Tables 2 and 3.

Although clinically functioning tumors were limited in the present study, the majority of the tumors had sporadically distributed tumor cells that were positive for peptide hormones. The functioning tumors had cells that were positive for several kinds of peptides (e.g., insulin-producing tumor also had ACTH-, glucagon-, and somatostatin-positive cells in addition to insulin-positive cells, as shown in Table 3). Because the two enzymes of PGM were located in the same cells, we describe them as PGM in the tables. CgA-positive cells were densely distributed in the normal mucosa adjacent to the carcinoids of the gastrointestinal tract (Fig. 1). CgA was detected in carcinoids, especially in the stomach, small intestine, and thymus carcinoids; however, $76 \%$ of the rectal carcinoids were focally positive or almost negative for CgA, despite showing many CgA immunoreactive cells in the normal rectal mucosa adjacent to the carcinoid (Fig. 2). In contrast, all 29 rectal-origin carcinoids were strongly positive for CgB (Fig. 3), whereas no or few cells were immunoreactive to $\mathrm{CgB}$ in the normal rectal mucosa adjacent to the carcinoids (Fig. 4). CgB was also detected in the other sites of carcinoids, including ovary, testis, and thymus. Three of seven gastric carcinoids were negative for CgB. PC3 was detected in all of the carcinoids (Fig. 5), whereas PC2 was observed in only 14 tumors (Table 2). PGM was highly expressed in 39 of the 45 carcinoids (87\%), including all of the rectal carcinoids (Fig. 6). There were no PC2-, PC3-, or PGM-immunoreactive cells in the normal mucosa of the gastrointestinal tract adjacent to the carcinoids.

In the pancreatic endocrine tumors, CgA was strongly expressed in all tumors, whereas $\mathrm{CgB}$ was not detected in any tumors. PC2 and PC3 immunoreactivity was observed in $10(63 \%)$ and $14(88 \%)$ tumors, respectively. All functioning tumors expressed PC3 (Fig. 7). PC2 was expressed in all insulinomas (Fig. 8) but not in any gastrinomas. PGM was expressed in all gastrinomas but not in two of eight insulinomas. PC2, PC3, and PGM immunoreactivity was observed in one, two, and one of the four nonfunctioning tumors, respectively.

TABLE 2. Immunoreactivity of $\mathrm{CgA}, \mathrm{CgB}, \mathrm{PC2}, \mathrm{PC} 3$, and PGM in Carcinoids

\begin{tabular}{llllcc}
\hline \multicolumn{1}{c}{ Tumor Site } & CgA & CgB & PC2 & PC3 & PGM \\
\hline Stomach $(n=7)$ & 7 & 4 & 1 & 7 & 1 \\
Rectum $(n=29)$ & 7 & 29 & 6 & 29 & 29 \\
Ileum $(n=2)$ & 2 & 2 & 2 & 2 & 2 \\
Testis $(n=2)$ & 2 & 2 & 2 & 2 & 2 \\
Ovary $(n=3)$ & 1 & 3 & 1 & 3 & 3 \\
Thymus $(n=2)$ & 2 & 2 & 2 & 2 & 2 \\
Total $(\%)(n=45)$ & $21(53)$ & $42(93)$ & $14(31)$ & $45(100)$ & $39(87)$ \\
\hline
\end{tabular}

Cg, chromogranin; PC, prohormone convertase; PGM, peptidylglycine $\alpha$-amidating monooxygenase.

\section{DISCUSSION}

Chromogranins constitute a family of watersoluble acidic glycoproteins that are present in almost all endocrine, neuroendocrine, and neuronal tissue. CgA and CgB have been known to undergo $\mathrm{pH}-$ and $\mathrm{Ca}(2+)$-dependent aggregation, and this property is considered essential for the proper sorting of the vesicular matrix proteins (19) and also are prohormones of several bioactive peptides $(20,21)$. Antibodies against chromogranins have been widely used for the diagnosis of endocrine tissues and tumors of neuroendocrine origin. The results of the present study revealed that the distribution of CgA in normal intestinal mucosa from the stomach to the rectum was intense, whereas $\mathrm{CgB}$ was sparse in the duodenum and essentially absent in other sites of the intestine. Both CgA and CgB have several cleavage sites and are processed to many low molecular fragments, some of which are identical to bioactive peptides $(20,21)$. CgB fragment (314-365) is also detected in endocrine tumors (22). Previous studies reported that CgA was either absent or immunolocalized only focally in tumors with a predominant trabecular pattern of colorectal carcinoids $(2,5,6)$.

Fahrenkamp et al. (23) investigated 152 neuroendocrine tumors of the gastrointestinal tract using monoclonal antibody against human CgA, CgB (amino acids 306-326), and CgC. They revealed that $\mathrm{CgA}$ is the major granin expressed in gastric carcinoids and in serotonin-producing carcinoids of the appendix and ileum. In contrast, strong $\mathrm{CgB}$ and CgC immunoreactivity was found in rectal carcinoids, in which CgA was rarely expressed. Although the epitopes of the $\mathrm{CgB}$ recognized by the antibodies used by Fahrenkamp et al. and us (amino acids 548-564) are different, their results are similar to our present findings, which indicates that $\mathrm{CgB}$ is a useful tumor marker for rectal and also ovarian and testicular carcinoids. The histogenesis of the rectal and ovarian carcinoids is interesting because there were numerous immunoreactive cells to CgA but no immunoreactive cells to $\mathrm{CgB}$ in the normal rectal mucosa and ovary. Measurements of plasma CgA $(24,25)$ and $\mathrm{CgB}(25)$ have been used as a reliable marker of neuroendocrine tumor growth.

Stridsberg et al. (25) measured plasma CgA and $\mathrm{CgB}$ in 44 patients with carcinoids and 17 patients with sporadic endocrine pancreatic tumors and observed elevated CgA and CgB plasma levels in 99\% and $88 \%$ of the patients, respectively. Our present study of pancreatic endocrine tumors revealed that all of the tumors strongly expressed CgA but not CgB. Scopsi et al. $(17,26)$ reported that 11 pancreatic islet cell tumors showed immunoreactivity to both CgA and CgB. The discrepancy between our results and those of Stridsberg et al. and Scopsi et 
TABLE 3. Immunohistochemical Results of CgA, CgB, PC2, PC3, PGM, and Hormones in 16 Pancreatic Endocrine Tumors

\begin{tabular}{|c|c|c|c|c|c|c|c|c|c|c|c|c|}
\hline Cases & CgA & CgB & PC2 & PC3 & PGM & Ins & Glu & SS & $\mathrm{PP}$ & Gast & ACTH & Clinical Diagnosis \\
\hline 1 & +++ & - & + & +++ & - & - & - & - & - & - & + & $\begin{array}{l}\text { Cushing } \\
\text { Syndrome }\end{array}$ \\
\hline 2 & +++ & - & - & + & ++ & + & + & - & - & ++ & - & Gastrinoma \\
\hline 3 & +++ & - & - & +++ & +++ & + & - & - & - & + & - & Gastrinoma \\
\hline 4 & +++ & - & - & ++ & ++ & - & - & - & - & + & - & Gastrinoma \\
\hline 5 & +++ & - & ++ & +++ & +++ & +++ & - & - & + & - & - & Insulinoma \\
\hline 6 & +++ & - & +++ & +++ & +++ & + & + & - & - & - & - & Insulinoma \\
\hline 7 & +++ & - & ++ & +++ & +++ & ++ & + & + & + & - & - & Insulinoma \\
\hline 8 & +++ & - & ++ & + & + & + & - & - & - & - & - & Insulinoma \\
\hline 9 & ++ & - & ++ & ++ & - & + & - & + & + & - & + & Insulinoma \\
\hline 10 & +++ & - & ++ & +++ & - & + & - & ++ & +++ & - & - & Insulinoma \\
\hline 11 & +++ & - & + & +++ & + & ++ & - & + & - & - & - & Insulinoma \\
\hline 12 & +++ & - & +++ & +++ & +++ & - & - & - & - & - & - & Insulinoma \\
\hline 13 & +++ & - & - & - & - & - & ++ & - & - & - & - & Nonfunctioning \\
\hline 14 & +++ & - & - & +++ & - & - & ++ & ++ & - & - & - & Nonfunctioning \\
\hline 15 & ++ & - & - & - & ++ & - & + & - & - & - & - & Nonfunctioning \\
\hline 16 & +++ & - & ++ & ++ & - & - & - & + & - & - & ++ & Nonfunctioning \\
\hline Total(\%) & $16(100)$ & $0(0)$ & $14(88)$ & $10(63)$ & $10(63)$ & $9(56)$ & $6(38)$ & $6(38)$ & $4(25)$ & $3(19)$ & $3(19)$ & \\
\hline
\end{tabular}

Cg, chromogranin; PC, prohormone convertase; PGM, peptidylglycine $\alpha$-amidating monooxygenase; Ins, insulin; Glu, glucagon; SS, somatostatin; PP, pancreatic polypeptide; Gast, gastrin; ACTH, adrenocorticotropic hormone; - , no immunoreactive cells; + , a few immunoreactive cells; ++ , more than $20 \%$ of tumor cells are immunoreactive; +++ , more than $50 \%$ of tumor cells are immunoreactive.

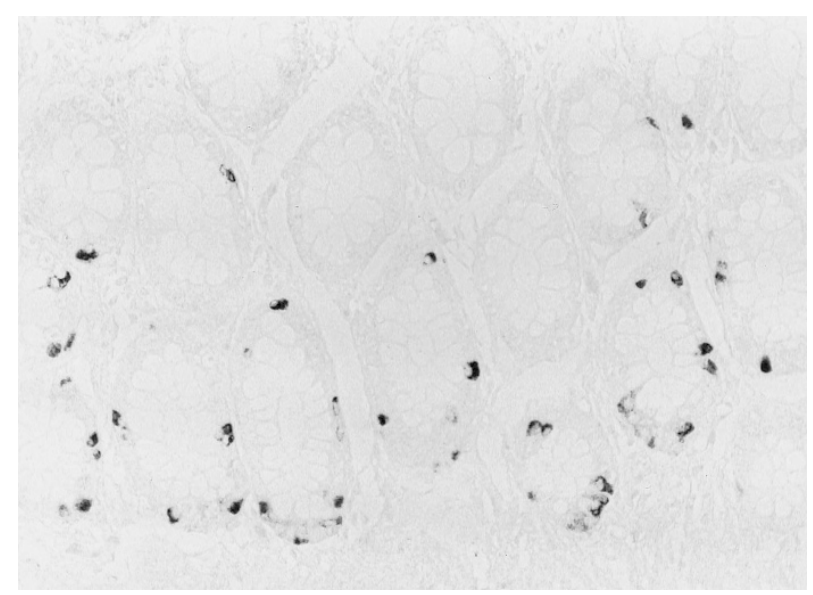

FIGURE 1. Normal rectal mucosa showing numerous chromogranin A-positive cells (original magnification, $200 \times$ ).

al. may be attributable to the different antibodies used against CgB. The antibody used by Stridsberg et al. and Scopsi et al. was raised against CgB extracted from a human pheochromocytoma. The amino acid sequence was not analyzed. Our antibody was raised against human CgB 548-564. The immunohistochemical expressions of chromogranins are different among species and also epitopes recognized by the antibodies (27).

Previous studies of prohormone convertases in human neuroendocrine tumors are limited in number, except for those on the pituitary gland and its tumors. Scopsi et al. showed that both PC2 and PC3 are virtually universal components of the neuroendocrine system; cells with a neural phenotype (e.g., pheochromocytes and Merkel cells) contained predominantly PC2, whereas classic endocrine cells contained mostly PC3 (17). In the present study,

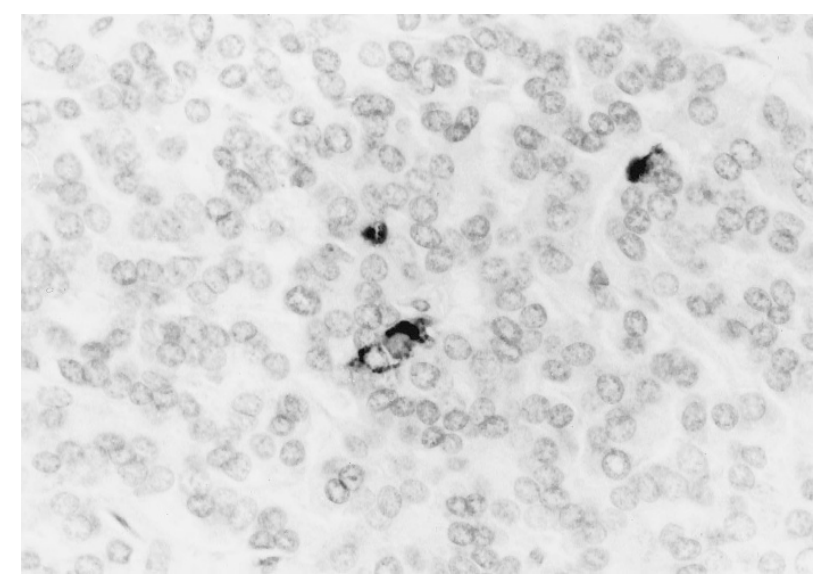

FIGURE 2. Rectal carcinoid; few tumor cells are immunoreactive to chromogranin A (lightly counterstained with hematoxylin; original magnification, $400 \times)$.

PC3 was expressed in all carcinoids and pancreatic endocrine tumors regardless of the kinds of hormones produced, whereas PC2 was expressed in $31 \%$ of the carcinoids, including 6 of 29 nonfunctioning rectal carcinoids and previously reported ACTH-producing thymic carcinoids (28) and serotonin-producing (only immunohistochemically examined) testicular carcinoids. Sixty-three percent of pancreatic endocrine tumors, including all insulin-producing tumors but no gastrin-producing tumors, showed cells that were immunoreactive to PC2. PC2 is known to mediate the processing of proopiomelanocortin, proinsulin, and perhaps serotonin. The high frequency of PC3 in nonfunctioning carcinoids and pancreatic endocrine tumors may explain why those nonfunctioning tumors have the ability to process some prohormones. The absence of expression of PC2 in carcinoids and 


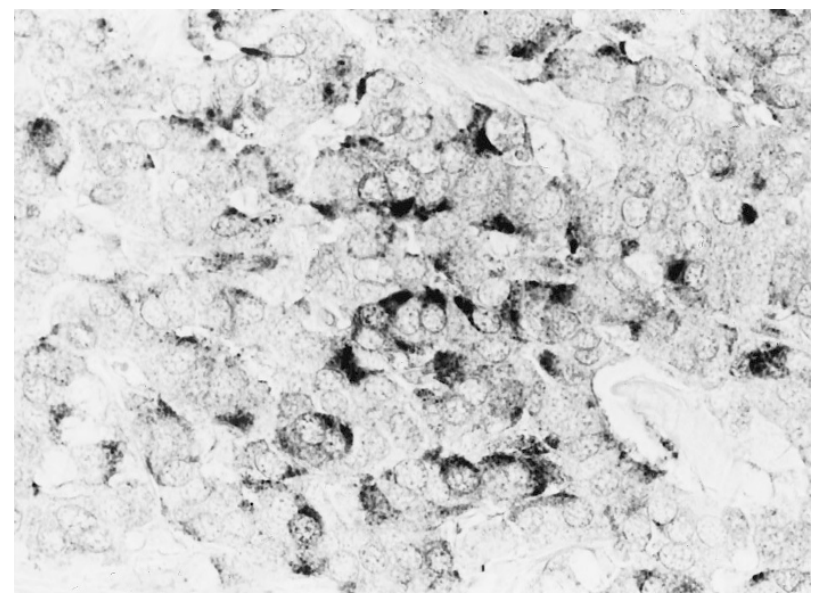

FIGURE 3. Rectal carcinoid (the same tumor as in Fig. 1); most tumor cells are positive for chromogranin B (lightly counterstained with hematoxylin; original magnification, $400 \times$ ).

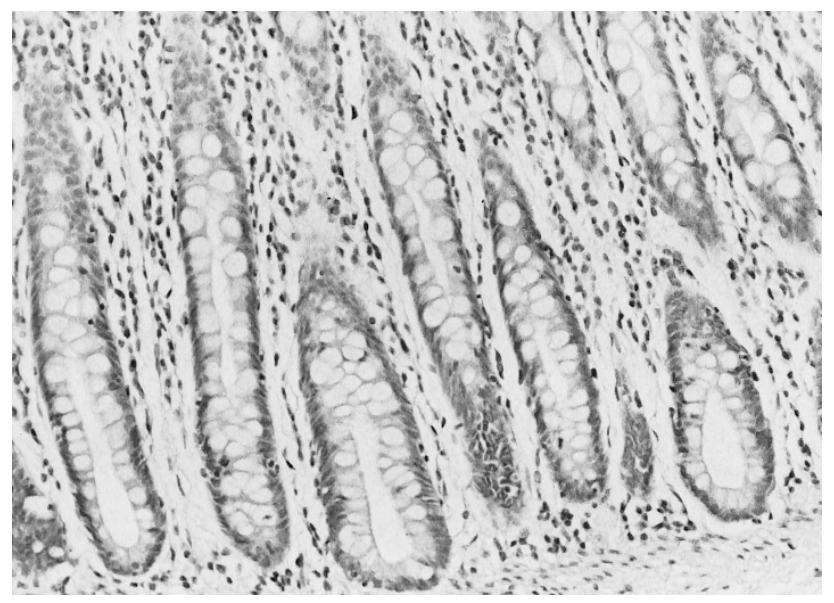

FIGURE 4. Normal rectal mucosa showing no cells that are

immunoreactive to chromogranin B (hematoxylin-eosin stain; original magnification, $200 \times$ ).

pancreatic endocrine tumors may relate to why some tumors are nonfunctioning.

Peptide $\alpha$-amidation is a posttranslational modification that occurs in approximately half of all endocrine and neuroendocrine peptide hormones $(29,30)$. Although no cells were immunoreactive to PGM in the normal mucosa adjacent to the carcinoids, most of the carcinoids except for the gastric carcinoids contained PGM. Our present study showed that not only the functioning tumors but also the clinically nonfunctioning tumors demonstrated highly frequent expression of PC3 and PGM. These results lead to the conclusion that the majority of endocrine tumors have the ability to produce some bioactive hormones and that most tumors produce inconspicuous peptides (that are not noticed clinically) and are considered to be nonfunctioning tumors. Functional tumors usually produce multiple hormones (31), and PCs and PGM may be required for producing them, including clinically unnoticed hormones.

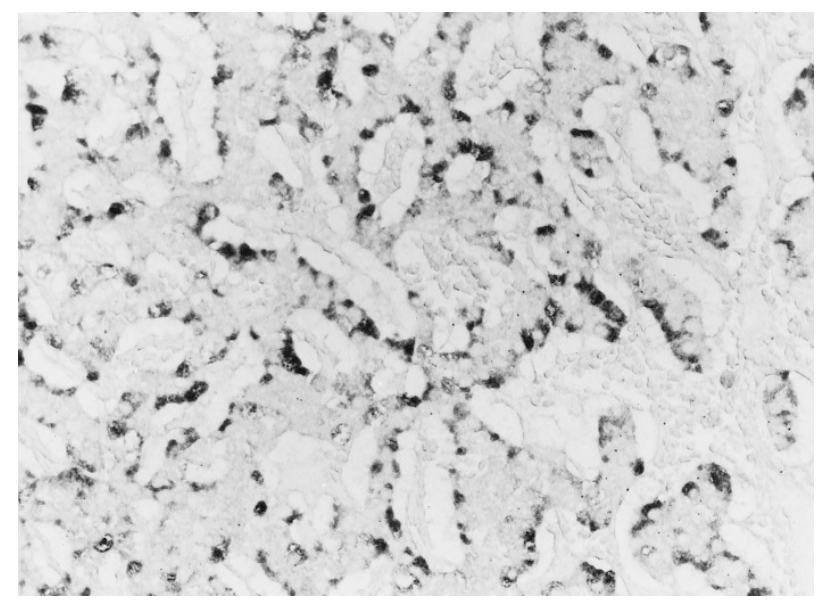

FIGURE 5. Rectal carcinoid; many tumor cells showing the immunoreactivity to PC3 (original magnification, 200×).

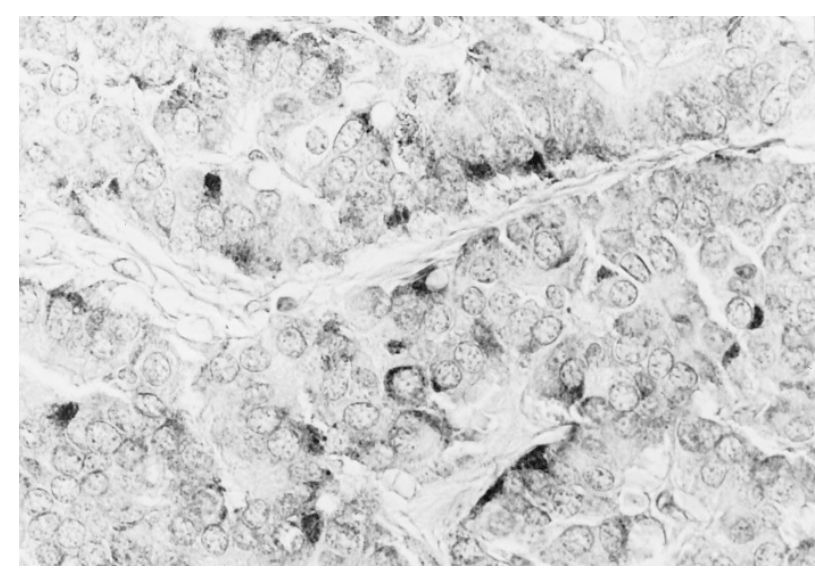

FIGURE 6. Rectal carcinoid; most tumor cells showing immunoreactivity to PGM (counterstained with hematoxylin; original magnification, $400 \times$ ).

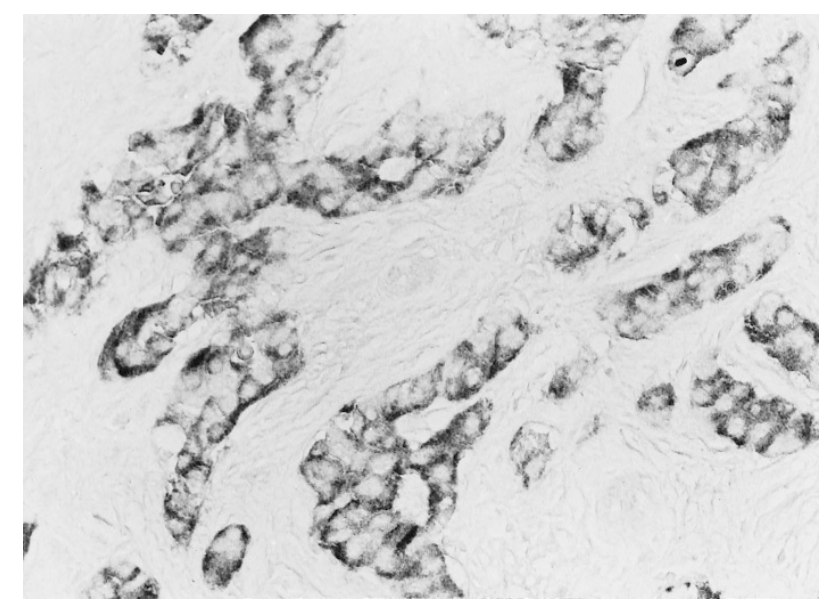

FIGURE 7. Pancreatic endocrine tumor; most tumor cells showing immunoreactivity to PC3 (original magnification, $200 \times$ ).

In conclusion, both functioning and nonfunctioning tumors had PCs and PGM. This indicates that even nonfunctioning tumors produce some hormones in greater or less degree. 


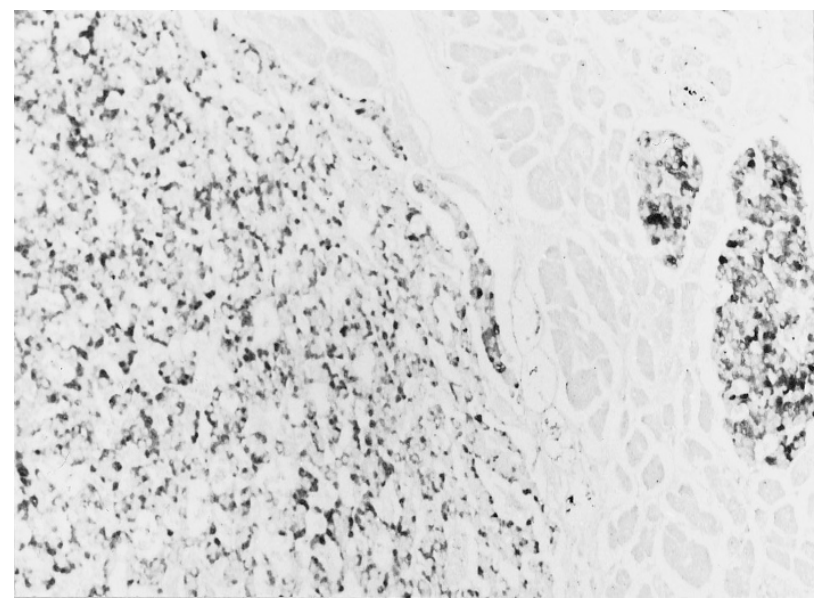

FIGURE 8. Pancreatic endocrine tumor (insulin-producing tumor); majority of the tumor cells showing immunoreactive positivity to PC2 as well as residual islets located on the right (original magnification, $100 \times)$.

Acknowledgments: We thank Dr. Donald F. Steiner, Department of Biochemistry and Molecular Biology, Howard Hughes Medical Institute, University of Chicago for supplying the antibodies for PC3.

\section{REFERENCES}

1. Capella C, Heitz PU, Hofler H, Solcia E, Kloppel G. Revised classification of neuroendocrine tumours of the lung, pancreas and gut. Virchows Arch 1995;425:547-60.

2. Kimura N, Sasano N, Yamada R, Satoh J. Immunohistochemical study of chromogranin in 100 cases of pheochromocytoma, carotid body tumour, medullary thyroid carcinoma and carcinoid tumour. Virchows Arch A Pathol Anat Histopathol 1988;413:33-8.

3. Kimura N, Funakoshi A, Aunis D, Tateishi K, Miura W, Nagura H. Immunohistochemical localization of chromostatin and pancreastatin, chromogranin A-derived bioactive peptides, in normal and neoplastic neuroendocrine tissues. Endocr Pathol 1995;6:35-43.

4. Pilichowska M, Kimura N, Ouchi A, Lin H, Mizuno Y, Nagura $\mathrm{H}$. Primary hepatic carcinoid and neuroendocrine carcinoma: clinicopathological and immunohistochemical study of five cases. Pathol Int 1999;49:318-24.

5. Federspiel BH, Burke AP, Sobin LH, Shekitha KM. Rectal and colonic carcinoids: a clinicopathologic study of 84 cases. Cancer 1990;65:135-40.

6. Perez MA, Saul SH, Trojanowski JQ. Neurofilament and chromogranin expression in normal and neoplastic neuroendocrine cells of the human gastrointestinal tract and pancreas. Cancer 1990;65:1219-27.

7. Lloyd RV, Cano M, Rosa P, Hille A, Huttner WB. Distribution of chromogranin A and secretogranin I (chromogranin B) in neuroendocrine cells and tumors. Am J Pathol 1988;130:296304.

8. Fischer-Colbrie R, Lassmann H, Hagn C, Winkler H. Immunological studies on the distribution of chromogranin A and $\mathrm{B}$ in endocrine and nervous tissue. Neuroscience 1985;16: 547-55.

9. Rnidi G, Buffa R, Sessa F, Tortora O, Solcia E. Chromogranin $\mathrm{A}, \mathrm{B}$, and $\mathrm{C}$ immunoreactivities of mammalian endocrine cells: distribution, distinction from costored hormones/prohormones and relationship with argyrophil component of secretory granules. Histochemistry 1986;85:19-28.
10. Vieau D, Massias J-F, Girard F, Luton J-P, Bertagna X. Corticotropin-like intermediary lobe peptide as a marker of alternate proopiomelanocortin processing in ACTHproducing non-pituitary tumors. Clin Endocrinol (Oxf) 1989; 31:691-700.

11. Thomas L, Leduc R, Trorne BA, Smeekens SP, Steiner DF, Thomas G. Kex2-like endoproteases PC2 and PC3 accurately cleave a model prohormone in mammalian cells: evidence for a common core of neuroendocrine processing enzymes. Proc Natl Acad Sci U S A 1991;88:5297-301.

12. Steiner DF, Smeekens SP, Ohagi S, Jin Chan S. The new enzymology of precursor processing endoproteases. J Biol Chem 1992;267:23435-8.

13. Vale W, Spiess J, Rivier J. Characterization of a 41-residue ovine hypothalamic peptide that stimulates secretion of corticotropin and beta-endorphin. Science 1981;213:1394-7.

14. Okamoto H, Kato I, Noguchi M, Takahashi K, Yonekura H, Anzai T, et al. Peptide $\alpha$-amidation is achieved by two distinct enzyme molecules encoded in a single mRNA. In: Yamamoto S, Nozaki M, Ishimura Y, editors. Proceedings of the Yamada Conference XXVII. Osaka, Japan: Yamada Scientific Foundation; 1991. pp. 113-6.

15. Yonekura H, Anzai T, Kato I, Furuya Y, Shizuta S, Takasawa $\mathrm{S}$, et al. Identification of the five essential histidine residues for peptidylglycine monooxygenase. Biochem Biophys Res Commun 1996;218:495-9.

16. Steel JH, Martinez A, Springall DR, Treston AM, Cuttitta J, Polak JM. Peptidylglycine $\alpha$-amidating monooxygenase (PAM) immunoreactivity and messenger RNA in human pituitary and increased expression in pituitary tumours. Cell Tissue Res 1994;276:197-207.

17. Scopsi L, Gullo M, Rilke F, Martin S, Steiner DF. Proprotein convertases (PC1/PC3 and PC2) in normal and neoplastic human tissues: their use as markers of neuroendocrine differentiation. J Clin Endocrinol Metab 1995;80:294-301.

18. Smeekens SP, Montag AG, Thomas G, Albiges-Rizo C, Carroll $\mathrm{R}$, Benig $\mathrm{M}$, et al. Proinsulin processing by the subtilisinrelated proprotein convertases furin, PC2, and PC3. Proc Natl Acad Sci U S A 1992;89:8822-6.

19. Yoo $\mathrm{SH}$. $\mathrm{pH}-$, and $\mathrm{Ca}(2+)$-induced conformational change and aggregation of chromogranin B: comparison with chromogranin A and implication in secretory vesicle biogenesis. J Biol Chem 1995;270:12578-83.

20. Simon JP, Aunis D. Biochemistry of the chromogranin A protein family. Biochem J 1989;262:1-13.

21. Strub J-M, Garcia-Sablone P, Lonning K, Taupenot L, Hubert P, Van Dorsselaer A, et al. Processing of chromogranin B in bovine adrenal medulla: identification of secretolytin, the endogenous C-terminal fragment of residues 616-626 with antibacterial activity. Eur J Biochem 1995;229:356-68.

22. Woussen-Colle MC, Gourlet P, Vandermeers A, Vandermeers-Piret MC, D'Haens J, Velkeniers B, et al. Identification of a new chromogranin B fragment (314-365) in endocrine tumors. Peptides 1995;16:231-6.

23. Fahrenkamp AG, Wibbeke C, Winde G, Ofner D, Bocker W, Fischer-Colbrie R, et al. Immunohistochemical distribution of chromogranins A and B and secretogranin II in neuroendocrine tumours of the gastrointestinal tract. Virchows Arch 1995;426:361-7.

24. Kimura N, Miura W, Noshiro T, Mizunashi K, Hanew K, Shimizu K, et al. Plasma chromogranin A in pheochromocytoma, primary hyperparathyroidism, and pituitary adenoma in comparison with catecholamine, parathyroid hormone and pituitary hormones. Endocrine J 1997;44:319-27.

25. Stridsberg M, Oberg K, Li Q, Engstrom U, Lundqvist G. Measurements of chromogranin A, chromogranin B (secretogranin I), chromogranin C (secretogranin II) and pancreastatin in plasma and urine from patients with carcinoid tumours and endocrine pancreatic tumours. J Endocrinol 
1995;144:49-59.

26. Scopsi L, Lee R, Gullo M, Collini P, Husten EJ, Eipper BA. Peptidylglycine $\alpha$-amidating monooxygenase in neuroendocrine tumors: its identification, characterization, quantification, and relation to the grade of morphologic differentiation, amidated peptide content, and granin immunocytochemistry. Appl Immunohistochem 1998;6:120-32.

27. Pelagi M, Bisiani C, Gini A, Bonardi MA, Rosa P, Mare P, et al. Preparation and characterization of anti-human chromogranin A and chromogranin B (secretogranin I) monoclonal antibodies. Mol Cell Probes 1989;3:87-101.

28. Kimura N, Ishikawa T, Sasaki Y, Sasano N, Onodera K, Shimizu Y, et al. Expression of prohormone convertase, PC2, in ACTH-producing thymic carcinoid with elevated plasma
CRH. J Clin Endocrinol Metab 1996;81:390-5.

29. Martinez A, Montuenga LM, Springall DR, Treston A, Cuttitta F, Polak JM. Immunocytochemical localization of peptidylglycine alpha-amidating monooxygenase enzymes (PAM) in human endocrine pancreas. J Histochem Cytochem 1993;41: 375-80.

30. Treston AM, Scott FM, Vos M, Iwai N, Mains RE, Eipper BA, et al. Biochemical characterization of peptide $\alpha$-amidation enzyme activities of human neuroendocrine lung cancer cell lines. Cell Growth Differ 1993;4:911-20.

31. Kimura N, Yamamoto H, Okamoto H, Wakasa H, Nagura H. Multiple-hormone gene expression in ganglioneuroblastoma with watery diarrhea, hypokalemia, and achlorhydria syndrome. Cancer 1993;71:2841-6.

\section{Book Review}

\section{Learmonth GW: An Atlas of Cytopathology of the Head and Neck: With Clinical and His- tological Correlation, 153 pp, London, Ar- nold, 1998 (\$89.50).}

An Atlas of Cytopathology of the Head and Neck is a single-author monograph that covers inflammatory, developmental, and neoplastic disorders. Generally, the book is well written with excellent illustrations. Special coverage is given to virtually all aspects of head and neck cytology. The book is organized into 10 chapters; 3 chapters are devoted to fine needle aspiration of lymph nodes, and 1 chapter each covers salivary gland tumors, cysts of the head and neck, oral cavity, nasopharynx, nose and paranasal sinuses, skin and soft tissue, and eye and orbit.

What is unique to this book is that the materials are presented in a case-oriented approach: one or two cases are presented for each disease; each case begins with a brief clinical history accompanied by clinical photographs or MRI scans; then a series of photomicrographs are displayed, including the standard Papanicolaou's stain and immunohistochemistry. Exfolia- tive cytopathology of the head and neck, which is not a common practice in the United States, receives good coverage.

Cytologic photomicrographs are in most cases accompanied by histologic pictures, which I found particularly useful for histologic correlation. The figure legends are concise and to the point.

As an atlas should, the book contains numerous illustrations on almost every page. These cytology photomicrographs are at a sufficiently high magnification, in color, and of exquisite sharpness.

Reviewing this book was an enjoyable and informative endeavor. Any pathologist, pathology resident, or cytotechnologist should benefit from having this as part of his or her bench top references and personal library.

\author{
Di Lu \\ Department of Pathology \\ University of Texas \\ MD Anderson Hospital \\ Houston, Texas
}

